\title{
Testing of Micro Switches for Garden Tools
}

\author{
V. SIPKÁS ${ }^{1}$, G. BOGNÁR ${ }^{2}$ \\ 1University of Miskolc, Institute of Machine and Product Design, machsv@uni-miskolc.hu \\ 2University of Miskolc, Institute of Machine and Product Design, v.bognar.gabriella@uni-miskolc.hu
}

Abstract. The aim of this paper is to introduce the design of testing method for the prediction of the life and acceleration methods of the micro switches applied in different type of garden tools. These products will be tested for complex stressing, for example higher temperature, humidity, current load and so on. Therefore, the most important information and multi-factor acceleration models are summarized, the Weibull, the lognormal and the exponential distributions which are suitable for performing and evaluating tests.

\section{Introduction}

Interpretation of accelerated test data requires models that relate accelerating variables like temperature, humidity, voltage, pressure and size to time acceleration. For testing over some range of accelerating variables, one can fit a model to the data to describe the effect that the variables have on the failure-causing processes. The general idea is to test at high levels of the accelerating variables to speed up failure processes and then to extrapolate to lower levels of accelerating variables. In the next chapters we shall summarize the most common acceleration models.

Our investigations aim to carry out pre-planned measurements and testing micro switches applied in garden tools. To obtain objective conclusions, we need an effective method for designing and analysing experiments $[4,5]$.

\section{Methods to predict failure mechanisms}

There are several type of failure predictions which can be used in research and in developments. These methods are further classified into different groups based on several technologies.

We shall introduce some of them in more detail, which are most likely to be applied for micro switches and research.

\subsection{Empirical methods}

The type of the methods based on the models to predict failure developed from historical data collected from filed, manufacturer or test data, is called empirical methods. These are easy to use and provide relatively good performance and approximation of field failure rates, but the data used is not device specific. So, approximation cannot be perfect. 


\subsection{Analytical methods}

To predict the failure, the analytical methods provide better approximation. Various numerical models are used to predict failure. For example, the following type of methods:

- Fault tree analysis (FTA) is a numerical approach to detect fault based on the simulation.

- Failure mode, mechanisms and effect analysis (FMMEA) is a systematic and anticipatory method that deals with step by step approach to identify the faults during the design or in service.

\subsection{Theoretical methods}

Physics of failure understands the failure mechanism and different models of physics can be applied for the data. For accurate prediction of wear-out failure of components, the analysis is costly, complex and detailed manufacturing characteristics of component are needed.

\subsection{Failure prediction method based on testing}

In life data analysis under normal operating conditions reliability is measured using a test which is conducted on large sample of units, time-to-failure are analysed using statistical distribution. Due to design or manufacturing, components are not independent, but physics of failure and empirical method assumes that there is no interaction between failures, so for realistic prediction at system level, life testing method is preferred over physics of failure or empirical method $[1,4]$.

\section{Micro switches}

In order the micro switch works properly when switched on and back on, it must be switched on and "prell number" allowed. Both will help to prevent and minimize curvature. When switching, the rate of change of arc and transition time decreases proportionally with the rate of separation. The switching time is determined primarily by the weight of the coupling force, the release force and the spring system. The pancreas may develop due to the following reasons: in the event of a collision, the moving contact repeatedly bends, due to the partially resilient collision and the swinging time of the snap spring. Platter number depends on: switch design, the click rate, frequency of switching, the hardness of the contact material.

The switches have the disadvantageous properties of the scroll. The essence of this phenomenon is that during switchover, the impact of the moving cake is not perfectly inelastic but partly flexible, so the moving bounces from the standing contact. In the event of a collision, the moving contact is bent repeatedly by a partially resilient collision and the swinging of the snap spring. The plating time and the number of squares depends on the construction of the switch, the rate of breakage, the frequency of switching and the hardness of the contact surface material [10]. 


\subsection{Failure modes of micro switches}

In $[6,7]$ the most common types of failures and the possible causes of their reasons have been shown.

There are many breakdowns of the micro switches on which multiple collectors are found, based on our previous experiences, previous customer complaints, warranty problems and test results.

Typical failure problem is the wear of the micro switch's switch-button, the deformation due to high temperature. Burning of contacting surfaces is also very common breakdown, material migration is the consequence of this phenomena $[6,8]$.

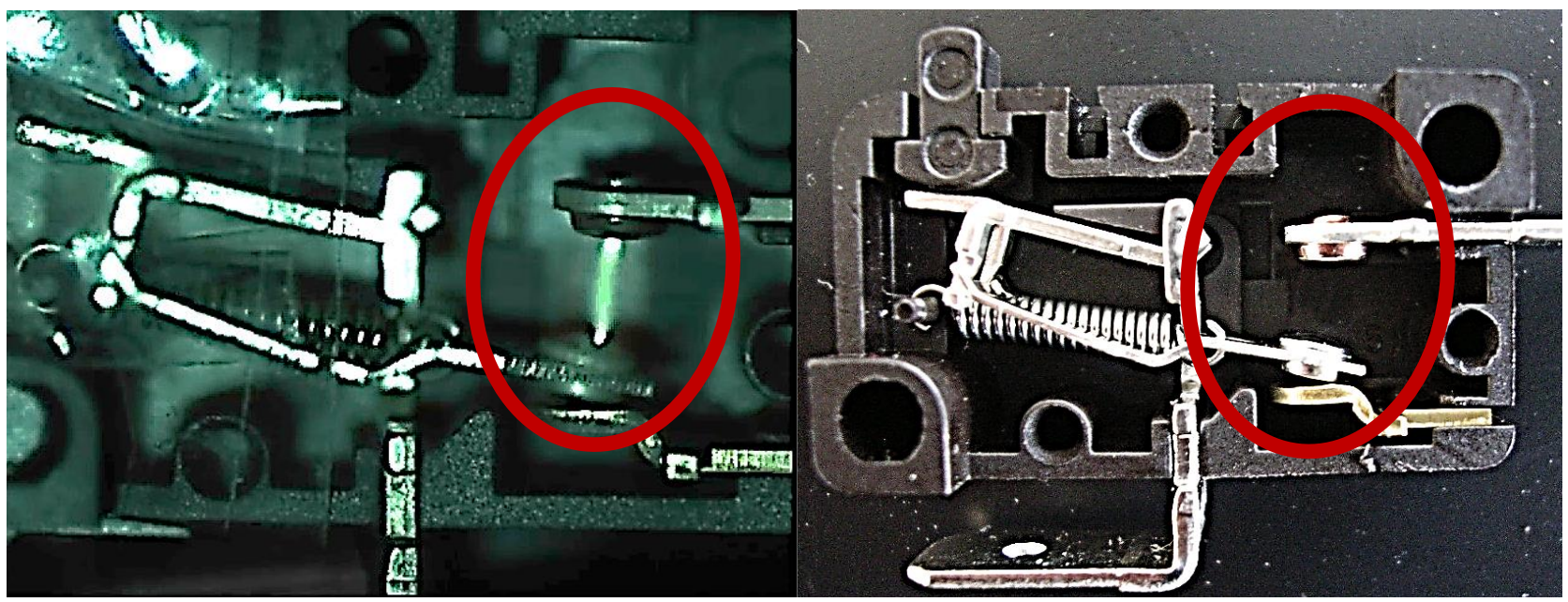

Figure 1. The arc formation

\subsection{The most common type of contacts}

As the failure defect is caused by the improper material or the incorrect design of the contacts, it is worth exploring the design, material and other features of the contact surfaces since these are one of the most important influencing factors.

\begin{tabular}{|c|c|c|c|}
\hline $\begin{array}{c}\text { Shape of } \\
\text { contact }\end{array}$ & Type & $\begin{array}{c}\text { Main } \\
\text { material }\end{array}$ & Main Application \\
\hline & $\begin{array}{c}\text { Crossbar } \\
\text { contact }\end{array}$ & $\begin{array}{l}\text { Gold } \\
\text { Silver } \\
\text { alloy }\end{array}$ & $\begin{array}{l}\text { These types of contacts are used for ensuring high contact } \\
\text { reliability for switching minute loads. } \\
\text { The movable contact and fixed contact come in contact with each } \\
\text { other at a right angle. Crossbar contacts are made with } \\
\text { environment-resistant material. }\end{array}$ \\
\hline
\end{tabular}




\begin{tabular}{|l|l|l|l|}
\hline \multirow{3}{*}{ Rivet } & $\begin{array}{c}\text { Silver } \\
\text { Silver } \\
\text { plated } \\
\text { Silver alloy } \\
\text { Gold plated }\end{array}$ & $\begin{array}{l}\text { Rivet contacts are used in wide application range from } \\
\text { standard to heavy loads. The fixes rivet contact is usually } \\
\text { processed so that it has a groove to eliminate compounds that } \\
\text { may be generated as a result of switching. Furthermore, to } \\
\text { prevent the oxidation or sulphuration of the silver contacts, the } \\
\text { contacts may be gold-plated while the switch is stored. Contacts } \\
\text { made with silver alloy are used for switching high current. }\end{array}$ \\
\hline \multirow{2}{*}{ Needle } & Silver & $\begin{array}{l}\text { Needle contacts are used for ensuring improvement in contact } \\
\text { reliability for switching, such as relays. It is made from rivet } \\
\text { contact by reducing the bending radius of the rivet contact to } \\
\text { approximately 1 mm for the purpose of the contact pressure } \\
\text { per unit area. }\end{array}$ \\
\hline
\end{tabular}

Table 1. Contact shape and type from switch catalogue [2, 3, 9]

\section{Distributions}

In this chapter, three types of distribution forms required for the examination and evaluation of micro switches are introduced. These are the Weibull distribution, the exponential distribution and the lognormal distribution.

\subsection{Weibull distribution}

Applying the general three-parameter form of the Weibull distribution, the distribution function can be formulated as follows:

$$
F(t)=\left\{\begin{array}{l}
1-\exp \left[-\frac{(t-\gamma)^{\beta}}{\alpha}\right], \text { if } t \geq \gamma \\
0, \text { if } t<\gamma
\end{array}\right.
$$

Function $F(t)$ gives the failure probability during the actual operating time. In formula (1) the statistical variable is time $t$ in hours or number of operations, the parameters involved in (1) are the following:

$\alpha>0$ is the scalar parameter,

$\beta>0$ is the shape parameter,

$\gamma \geq 0$ is the location parameter.

The characteristic lifetime is denoted by $\eta$. Let us introduce the substitution $\eta=\alpha^{1 / \beta}$ into expression (1). Thus, the distribution function can be written as follows:

$$
F(t)=\left\{\begin{array}{rr}
1-\exp \left[-\left(\frac{t-\gamma}{\eta}\right)^{\beta}\right], & \text { if } t \geq \gamma \\
0, & \text { if } t<\gamma .
\end{array}\right.
$$


The position parameter $\gamma$ can be taken to 0 for a few practical applications, the sampling plans are designed for case $\gamma=0$. The shape parameter $\beta$ determines the figure of the density function. The density function $f(t)$ for the Weibull distribution when $\gamma=0$ can be determined by differentiation from formula (1a) (see Fig. 2).

$$
f(t)=F^{\prime}(t)=\left\{\begin{array}{c}
\frac{\beta}{\eta}\left(\frac{t}{\eta}\right)^{\beta-1} \exp \left[-\left(\frac{t}{\eta}\right)^{\beta}\right], \text { if } t \geq 0, \\
0, \\
\text { if } t<0 .
\end{array}\right.
$$

If $\beta<1$, then $f(t)$ is a monotone decreasing function, this is the phase of early failures.

If $\beta=1$, then we get the exponential distribution, which is the phase of random failures.

If $\beta>1$, then density function has a maximum, this characterize the phase-related failure phase [4-8].

The failure rate as a function of time for the case of $\gamma=0$ can be obtained as:

$$
\lambda=\frac{f(t)}{1-F(t)}=\left\{\begin{array}{lll}
\frac{\beta}{\eta}\left(\frac{t}{\eta}\right)^{\beta-1} & \text {, if } & t \geq 0 \\
0, & \text { if } & t<0
\end{array}\right.
$$

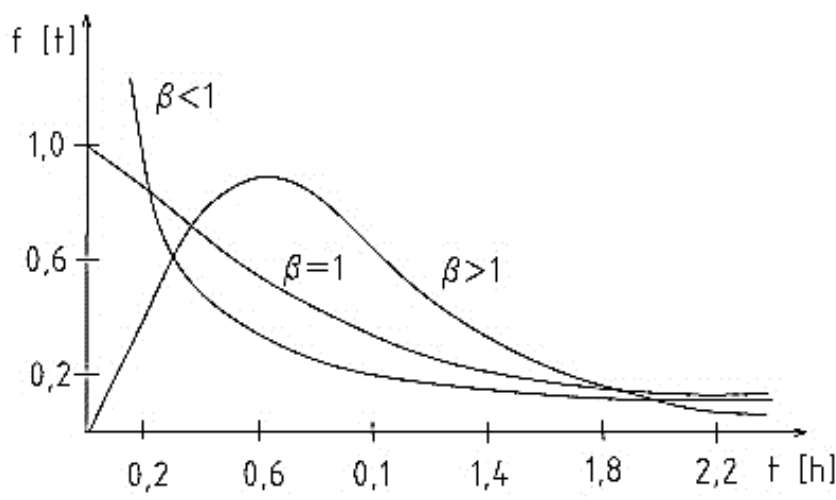

Figure 2. The density function of the Weibull distribution for different values of $\beta$

\subsection{Exponential distribution}

When $t$ has an exponential distribution, then the two-parameter exponential distribution (to distinguish it from the more commonly used one-parameter exponential distribution) has distribution function, the density function and the failure rate as follows

$$
\begin{aligned}
& F(t ; \Theta, \gamma)=1-\exp \left(-\frac{\mathrm{t}-\gamma}{\theta}\right) \\
& f(t ; \Theta, \gamma)=\frac{1}{\theta} \exp \left(-\frac{\mathrm{t}-\gamma}{\theta}\right)
\end{aligned}
$$




$$
\lambda(t ; \Theta, \gamma)=\frac{1}{\theta}, \quad \mathrm{t}>\gamma
$$

where $\Theta>0$ is a scale parameter and $\gamma$ is both a location and a threshold parameter. For $\gamma=0$ this is the well-known one-parameter exponential distribution (known as the exponential distribution).

The exponential distribution is an often-used distribution for different type of electronic components (e.g., capacitors or robust, high-quality integrated circuits). This exponential distribution would not be appropriate for a population of electronic components having failure-causing quality defects (such defects are difficult to rule out completely and are a leading cause of electronic system reliability problems) $[4,5]$.

\subsection{Lognormal distribution}

When the random variable (time) $t$ has a lognormal distribution, then the distribution function and the probability density function can be formulated

$$
\begin{array}{r}
F(t ; \mu, \sigma)=\Phi_{\text {nor }}\left[\frac{\log (\mathrm{t})-\mu}{\sigma}\right], \\
f(t ; \mu, \sigma)=\frac{1}{\sigma t} \varphi_{\text {nor }}\left[\frac{\log (\mathrm{t})-\mu}{\sigma}\right],
\end{array}
$$

where $\Phi_{\text {nor }}$ and $\varphi_{\text {nor }}$ are probability density function and cumulative distribution function for the standardized normal, and $\mu$ is the location parameter $\sigma>0$ is a shape parameter.

The definition of the lognormal distribution uses the natural logarithms with base $e$. The common logarithms wit base 10 are also used in some areas of application. The definition of the parameters $\mu$ (mean of the logarithm of $t$ ) and $\sigma$ (standard deviation of the logarithm of $t$ ) will depend on the base that is used.

\section{Acceleration models with two accelerating factors}

In some accelerated tests more than one accelerating variable are used. Such tests might be suggested when it is known that two or more potential accelerating variables can be applied for the lifetime prediction.

\subsection{Temperature-(voltage) stress acceleration}

The terms with $x_{1}$ and $x_{2}$ correspond, respectively, to the Arrhenius and the power relationship acceleration models. The term with $x_{3}$, a function of both temperature and voltage, is an interaction suggesting that the temperature - acceleration factor depends on the level of voltage. A voltagetemperature interaction suggests that the voltage-acceleration factor depends on the level of temperature. The degradation process at time $t$ can be determined by 
International Journal of Engineering and Management Sciences (IJEMS) Vol. 4. (2019). No. 1

$$
D(t)=\delta_{0}[\mathcal{R}(\text { temp, volt }) \times t]^{\frac{1}{\gamma_{1}}}
$$

where $\gamma_{1}$ is regression parameter, $\delta_{0}$ is the size of the risk and the reaction rate $\mathcal{R}($ temp, volt $)$ is the following:

$$
\mathcal{R}(\text { temp, volt })=\gamma_{0} x(\text { temp } K)^{m} \mathrm{x} \exp \left(\frac{-E_{a}}{k_{B} \times \operatorname{temp} K}\right) \times \exp \left(\gamma_{2} \log (\text { volt })+\frac{\gamma_{3} \log (\text { volt })}{k_{B} \times \text { temp } K}\right),
$$

where the $x_{1}=11605 /$ tempK $, x_{2}=\log ($ volt $), x_{3}=x_{1} x_{2}$.

Failure occurs when $\mathcal{D}(t)$ (level of degradation time $t$ ) crosses $\mathcal{D}_{f}=$ applied voltage stress, denoted by volt. Equating $\mathcal{D}(t)$ to volt and solving for failure time $\mathrm{T}$ gives

$$
T(\text { temp }, \text { volt })=\frac{1}{\mathcal{R}(\text { temp }, \text { volt })}\left(\frac{\text { volt }}{\delta_{0}}\right)^{\gamma_{1}} .
$$

Then, the ratio of failure times at $\left(\right.$ temp $_{U}$, volt $\left._{U}\right)$ versus (temp, volt) is the acceleration factor:

$$
\begin{gathered}
\mathcal{A F}(\text { temp, volt })=\frac{T\left(\text { temp }_{U}, \text { volt }_{U}\right)}{T\left(\text { temp }_{\text {volt }}\right)} \\
=\exp \left[E_{a}\left(x_{1 U}-x_{1}\right)\right] \times{\frac{\text { volt }^{\gamma_{2}-\gamma_{1}}}{\text { volt }_{U}}}^{\mathrm{x}}\left\{\exp \left[x_{1} \log (\text { volt })-x_{1 U} \log \left(\text { volt }_{U}\right)\right]\right\}^{\gamma_{3}},
\end{gathered}
$$

where $x_{1 U}=11605 /\left(\right.$ temp $\left._{U} K\right)$ and $x_{1}=11605 /$ tempK . For the special case when $\gamma_{3}=0$ (no interaction), $\mathcal{A F}($ temp, volt) is composed of separate factors for temperature and voltage acceleration. in this case the voltage-acceleration factor (holding temperature constant) does not depend on the temperature level used in the acceleration $[4,5,8]$.

\section{Conclusion}

In this paper, the practical and mathematical methods required for the further process of research are introduced. Previously, the possibility of defective micro switches in the most common cases is shown. Based on the failure modes, it can be seen that the design and construction of the products greatly influence their life cycle and their correct functioning. Therefore, we looked at the core recommendations of the catalogues for the contacts. In the second part of this paper, the most important information about Weibull, lognormal and exponential distributions, and acceleration models with more accelerating factors, that will be relevant later are summarized. 


\section{Acknowledgments}

$\Rightarrow$

The first author is supported by the ÚNKP-18-3-I-ME/19. New National Excellence Program of the Ministry of Human Capacities. For the second author Project no. 129257 has been implemented with the support provided from the National Research, Development and Innovation Fund of Hungary, financed under the K_18 funding scheme.

\section{References}

[1] C. Bhargava - V. K. Banga - Y. Singh (2014) Failure Prediction and Health Prognostics of Electronic Components: A review, Proceeding of 2014 RAECS UIET Panjab University Chandigarh, 06-08 March, 2014, IEEE 978-1-4799-2291-8/14

[2] Cherry - Micro -switches Catalogues

[3] Omron Technical Information, Snap Action Switches, pp. 914-926.

[4] W. Q. Meeker - L. A. Escobar (1998) Statistical Methods for Reliability Data. WileyInterscience Publication - John Wiley\& Sons, INC, Copyright. ISBN 978-0-471-14328-

[5] W. Nelson (1990a), Accelerated Testing: Statistical Models, Test Plans, and Data Analyses. New York: John Wiley \& Sons.

[6] V. Sipkás - G. Bognár (2018) The Application of Accelerated Life Testing Method for Micro Switches. International Journal of Instrumentation and Measurement. Vol. 3. pp. 1-5. ISSN 2534-8841

[7] V. Sipkás - G. Vadászné Bognár (2017) Mikrokapcsolók gyorsított élettartam vizsgálata. Gépipari Tudományos Egyesület Műszaki Folyóirat. . (GÉP). 68 (4) pp. 57-60 (in Hungarian)

[8] V. Sipkás - G. Vadászné Bognár: Failure Prediction Models for Accelerated Life Tests. Design of Machines and Structures (in press)

[9] RS Components, (rscomponents.hu), pp 1129-1137

[10] N. Bárány (1974) Finommechanikai kézikönyv. Műszaki könyvkiadó. (in Hungarian) 